\title{
Benefits of Knowledge Acquisition Systems for Management. An Empirical Study
}

\author{
Moh'd Alsqour \\ Wroclaw University of Economics \\ ul. Komandorska118/120, \\ 53-345 Wroclaw, Poland \\ Email: mohsqour@wp.pl
}

\author{
Mieczysław L. Owoc \\ Wroclaw University of Economics \\ ul. Komandorska 118/20, \\ 53-345 Wroclaw, Poland \\ E-mail:mieczyslaw.owoc@ue.wroc.pl
}

\begin{abstract}
The main objective of conducting this study is to shed light on the benefits and role of data warehouse (DW) as a source of knowledge acquisition in enhancing the process of decision-making. It is believed and assumed that meaningful and significant information can be acquired from DW which provides valuable knowledge to support business process and decision-making.

The theoretical assumptions are supported by the results of a questionnaire survey, which was conducted on top management of Jordanian firms. The questionnaire was developed based on the findings from related literature and other related research questionnaires. Over 250 firms, which were listed on Amman Stock Exchange (ASE) at the time of data collection, were involved in the survey. The researchers arrived at scores of significant and remarkable results regarding $D W$ and its benefits and role in enhancing the process of decision-making. In general, the respondents had a positive attitude towards the use of DW.
\end{abstract}

\section{INTRODUCTION}

1 'oday's organizations face a very hard time, largely as a result of competition, globalization, automation and scarcity of resources. As the business environment is changing. At the same time, those companies are likewise evolving. In this changing environment, companies are much more eager in getting immediate and accurate information to make better decisions. Successfully supporting managerial decision-making has become critically dependent upon the availability of integrated and high quality information organized and presented to managers in a timely and easily understood manner ([1]; [2]; [3]).

In such environments it is important to assure decisionmakers of the quality of data they use ([13; [12]). [16] claim that Data warehouse (DW) hastens the process of retrieving information needed for decision-making. DW technology has emerged as a key source and powerful tool for delivering and accessing information for decision-makers ([4]; [1]; [5]; [6]; [7]; [3]). Since the 1990s ([8]; [9]), DWs have been an essential information technology (IT) strategy component for large and medium-sized global organizations [8].

Despite the recognition of data warehousing as an important area of practice and research, there is little empirical research ([3]; [17]) about implementation of DW in general ([18]; [14]; [17]; [3]).
Timely and informed decision-making is becoming crucial for the long-term success of businesses [20]. [21] claims that business decisions must be made with speed and accuracy if organizations are to remain competitive. There is quasi-consent that DW provides more detailed and accurate information for decision-makers to improve their decisions. Considering the usefulness of DW there has been little research in Jordan on DW, i.e. it has been comparatively less investigated in Jordan (exceptionally our last paper during KAM'14 - see [76]. Therefore, the main focus of this study is on the advantages and benefits of DW as a provider of information to the process of decision-making. It investigates mainly the relation between decision-making, the need for information and the employment of DW in Jordanian firms.

In addition, this study investigates how top management of Jordanian firms perceives the effectiveness (usefulness) of DW as a source of reliable and accurate information for decision-making.

\section{AIM OF THE STUDY}

In this paper, a field study of DW and its benefits and role in easing and enhancing the process of strategic decisionmaking among top managers in Jordanian firms were investigated. Therefore, the main aim of this study is to investigate the benefits, which are provided by DW, in enhancing the process of decision-making.

It has been ascertained that DW is superior to traditional database and improves the process of decision-making. Therefore, the study's aim is to investigate empirically whether or not the DW provides better and more accurate information.

A study of a large number of data warehousing practitioners and experts by [24] showed that the implementation of DW was motivated more by internal pressures than external. A majority of the respondents said that the need was information related, including the need for better access to information, more accurate information and a single source of data. As the authors point out, organizations appear to initiate DW projects to provide decision-makers with accurate and effective information. [25] are of the opinion that improving access to information and delivering better and more accurate information are motivations for using DW. 


\section{THE NOVELTY VALUE OF THE STUDY}

This study was applied in Jordan, which is one of the developing countries in the Middle East. As Jordan's firms are not in isolation from the rest of the world, they are also influenced by the current competitive environment. The implementation of advanced and recent innovations, such as DW, is essential for the firms in developing economies, such as Jordan.

Despite the exaltation and adulation of DW, there is a need for evidences that the implementation of DW improves the quality and accessibility to information. Therefore, this study aims to practically investigate whether or not the implementation of DW improves the quality and accessibility to information and enhances the process of decision-making. Doherty and Doig in [26] drew attention to the role and importance of information accessibility. The authors claim that the information accessibility is a precursor of information quality-it has a significant impact on the information's usage, and consequently is an indicator of the DW's success in storing and processing information.

In addition to information's quality, previous literature and studies on DW have emphasized the importance of accessing information. The accessibility to information and their quality are crucial to the success of their use. It has been claimed that the use/ implementation of DW improves the quality and accessibility to information, and consequently leads to sound decisions. In other words, it leads to more fact-based decisions. DW has, according to DW literature, the ability to store a vast amount of data in a usable and appropriate form for the decision-makers' needs and uses. Although a wide range of primary and secondary sources has emphasized the importance and role of information quality and accessibility in enhancing the process of decision-making, little empirical research has been conducted so far. Such claims need to be tested empirically. It is essential, therefore, that the researchers investigate whether or not DW provides easy access to data and information, frequent, accessible and timely reports and more accurate, useful, reliable, complete and relevant information to decision-makers.

Based on extensive literature review, the researchers have identified that firms are often unsuccessful due to a lack of appropriate information or more precisely their inability to get the right information to the right person at the right time. The availability of apposite information to decision-making helps mangers in taking reliable decisions, which improve the firm's performance.

Additionally, the researchers have not found and are completely unaware of any empirical studies regarding the implementation of DW in Jordan. Therefore, it is hoped that the findings of this study give the readers and those who are interested in these issues practical insights into DW's field in Jordan. To some extent, it is one of the academic contributions. It contributes to our understanding of the DW in general and in Jordan in particular, and may form a basis and motivation for future research in the important fields. It is also believed that the final outcome of this paper adds up to the improvement and development in DSS, such as DW, by helping their users and developers to be more aware of the data and information's quality.

\section{RESEARCH METHODOLOGY}

The writing of this paper is passed in different phases. In the initial phases of the study, renowned journals, publications, conferences proceedings and books were reviewed. In addition to these sources, the findings of numerous empirical studies were researched and analyzed. As the researchers previously pointed out, the sample of the study comprises all the 277 firms, which are listed on ASE at the time of the data collection. Thus, a questionnaire was found to be the best instrument for collecting the data in this study. During the next phases, therefore, a survey questionnaire was conducted with the top managers of Jordanian firms. The questionnaire, which is used in this study, is based on previous studies and the researchers' assessments and discretion and adapted to suit the objectives and requirements of the study.

The data, which were collected, is very quantitative in nature. Therefore, in the final phases of the study, the data were statistically analyzed by employing Statistical Package for the Social Sciences (SPSS) in order that proper descriptive and inferential statistics to analyze the results and draw conclusions can be reached, including means, frequencies, standard deviation,.

\section{V.LITERATURE REVIEW}

The concept of data warehousing has evolved out of the need for easy access to a structured store of quality data that can be used for decision-making [27 p. 5]. Organizations have vast amounts of data but have found it increasingly difficult to access it and make use of it [27 p. 5].

As an attempt to solve the problem, DWs were introduced. DWs have become the focal point for decision support in organizations today [28]. [27 p. 5] claim that the data warehousing offers a better approach. Data warehousing implements the process to access heterogeneous data sources; clean, filter, and transform the data; and store the data in a structure that is easy to access, understand, and use. The data is then used for query, reporting, and data analysis [27 p. 5]. [29] also claim that the data warehousing has emerged as an effective mechanism for converting data into useful information.

DW systems offer efficient access to integrated and historical data from heterogeneous sources to support managers in their planning and decision-making [30]. [31] also claim that data warehousing provides an infrastructure that enables businesses to extract, cleanse, and store vast amounts of data. Most medium to large organizations, according to [32], operate DWs.

It has been claimed that the main DW's role is to support decision-making. However, the role of DWs has been broadened. [33] state that DW provides information from 
external data sources for decision-making. DW has the potential to create radical changes to existing business processes and is often viewed within the context of business process reengineering [18]. Accordingly, [34] claims that DW gives business' users the ability to analyze data. [35] also claim that DWs enable organizations to exploit decision-making.

According to [36], DWs provide the basis for management reports and decision support. In support of the above mentioned claims participants to a study by [6] agreed that the Return on Investment (ROI) for the DW was well justified through considerable gains in productivity and enhanced quality of customer service. Moreover, in an independent detailed study of 62 organizations worldwide ([34]; [37]), the major findings of International Data Corporation (IDC) based upon 62 case studies of organizations that have successful DWs in use are an average three-year ROI of 401percent was realized by organizations building DWs. Although this study is primarily focused on quantitative information, there are several qualitative benefits ([34]; [37]), such as providing standardized, clean and value-added data to create information from disparate sources. In addition, the DW makes the data available across corporate organizations and provides the needed information quickly.

The DW is developed in order to support the integration of external data sources ([38]; [39]) for the purpose of advanced data analysis. [40 p. 35] argues that a DW produces tangible impacts to the quality of day-to-day business transactions. Previous research on DW has produced some encouraging findings about its benefits and indicated that a DW can offer several benefits to an organization [18], such as enabling effective decision support; ensuring data integrity, accuracy, security, and availability; easing the setting and enforcing of standards, facilitating data sharing, and improving customer service [35]. [41] presented time savings for data suppliers and for users, more and better information, better decisions, improvement of business processes, and support for the accomplishment of strategic business objectives as benefits from data warehousing.

Furthermore, [5], who examined data warehousing at the Housing and Development Board (HDB) in Singapore, found that the main benefits of the DW, which were developed by HDB, are enabling the users to have access to consistent and reliable data in a timely fashion which facilitated forecasting and planning efforts and improved decision-making. In addition, a study by [42] revealed that DW appears to be used more to improve the flow of information in an organization than to change the way the organization does business. The authors found that more and better data is the greatest realized benefit from DW. Moreover, a study by [43] identified time savings, new and better information, and improved decision-making as benefits of DW.
[44] conducted an explanatory case study at a financial services organization to investigate how DW provides decision support to individual decision-makers. The results showed that the organizations successfully automated the retrieval and input of data for front-end users. [40 p. 33-34], who interviewed people from seven companies, found that the benefits of implementing DW were improving asset management, reducing customer support costs, auditing billing practices, terminating unprofitable product, reducing staff requirements and running the business. [28], who described the DW implementation at Blue Cross and Blue Shield of North Carolina (BCBSNC), claim that the DW had resulted in many organizational benefits, including better data analysis and time savings for users. [45], who looked at the DW of Egypt's Cabinet Information and Decision Support Center, found that the DW provides a lot of benefits to the users, including ease of access to the information, fast and more consistent reports, support the decision-makers and integrating the data from various sources.

Additionally, [7], who conducted a laboratory experiment in 2006, found that the implementation and use of DW improves the DSS users' decision performance, by which he means improving the quality of the DSS by adding a DW can improve information availability and quality and enhance DSS users' decision performance. In conclusion, the study showed that DW can have a positive impact on decision-making.

[46], who described an example of implementing DW in medical institutions, found that the DWs provide the users access to important information. [47], who conducted a survey to find out how DW assists decision-making process in healthcare, found that the DW provides better accessibility to data, integrated disparate data sources and improved decision-making. [48] found that all companies, which are studied, recognized some benefits such as cost reduction, reach-out to other markets, increase in sales, time saving in amount and preparation of reports and more effective decision-making based on the obtained information. [49], who conducted two case studies on American Airlines and Hallmark Cards, found the easy to use, speedy information retrieval, more information, better quality information, improved productivity, and better decisions as benefits of DW. [50], who examined the implementation of DW in public security, found that the DW is very important in improving the comprehensive ability of leadership and decision-making. In addition, it quickly and efficiently integrates heterogeneous data sources.

Previous literature on DW, such as [42] and [30], claims that the DW does not create value by itself; the value comes from the use of the data in the DW. [30] claim that improved decision-making results from the better information available in the DW. By making the right information available at the right time to the right decision-makers in the right manner, DWs empower the users with the ability to make the right decisions [51]. [42] also claim that this use can result in numerous benefits, including more and better 
information, improved user ability to produce information and reduced effort by developers to produce information. [52] also maintain that DWs have tremendous potential to present information. The greatest potential benefits of the DW occur when it is used to redesign business processes and to support strategic business objectives [41].

[53] also identified many different measures of success; these include benefits such as data accuracy, useful information, accurate information, ease of use, user satisfaction, time to make decision and increased revenue. However, [54] claims that despite clear evidences that many DW projects have resulted in interesting business benefits, there are also many examples of cost and schedule overruns and dissatisfaction regarding the results from these projects. [55] argue that DW is one of the key developments in the IS field and has plentiful benefits. In addition, [56] indicates that the introduction of a new IS into an organization should deliver multiple benefits.

Since the early 1990s, DWs have become the technology of choice for building data management infrastructures [8] and been investigated and implemented around the world in many areas and by many researchers, authors, and scholars [57]. According to [58] p. 13, the early successful implementation of DW dates back to mid-1980s at ABN AMRO Bank (Netherlands). The author claims that the enduser's needs were the key feature behind the implementation. As a result, those requirements were modeled rather broadly, and all available data was stored in the DW. In fact, in the first few years of general use, its usage had grown at an annual rate of $50 \%$, and by 1995 the DW had supported some 3,000 end-users. [58 p. 17] also mentioned that a study of 62 DW projects, which was conducted in 1996, showed an average return on investment (ROI) of $321 \%$ for these enterprise-wide implementation in an average payback period of 2.73 years.

In addition, [59], who investigated whether lodging companies are involved with DW technology through a sample of twelve large lodging corporations, found that the most of hotel corporations in the study were using their DWs to support market analysis. However, [13], who conducted a survey on a large Australian public organization, found that $60 \%$ of the users were with limited or no usage (or were anticipating the use in the future) of the DW. The data also helped the users to make informed decisions and the data, which was retrieved from the DW, was also presented to the senior management and other strategically oriented sections in the form of reports i.e. annual and quarterly reports.

Similarly, [18], who surveyed DW's managers and data suppliers from 111 organizations in different regions of the United States (US), also found that all companies had operational DW and nearly all of them considered that their initiative is successful. In other words, $26 \%$ of the respondents considered it runaway success. Another survey by Forrester showed that 878 IT decision-makers in the US enterprises were somewhat satisfied with the accessibility and quality of customer information; $82 \%$ of these respondents are satisfied or very satisfied [60]. [35] also found that about $55 \%$ of 196 respondents firms (107) in two major states in the US had already adopted and used DWs.

Similarly, [23] p.192-196 found that $60 \%$ of the respondents consider the functionality of their DW below expectations. $40 \%$ of the dissatisfied group was actually still using it. This means that $80 \%$ of the respondents were still using their internal DW, which is a good indication of the overall degree of satisfaction.

In addition to those studies, [61], who reported the results of a survey which was conducted at The Data Warehousing Institute (TDWI) World Conference in New Orleans 2003, found that $45 \%$ of the respondents had been already in production with their current DW or implementing a second or third release.

The 2007's IBM Data Warehousing Satisfaction Survey showed that $56 \%$ of those questioned were very successful with their DW (200 end-user enterprises were participated), however, $43 \%$ of the respondents acknowledged the need for improvement, as there are still a number of business and technical challenges confronting the enterprises which make use of DWs according to the survey [64]. The success of DW's implementation, according to [64], is growing as 56\% of the respondents were very successful and satisfied. [65], who conducted a survey on 84 users of DW, found that the majority of respondents $(73 \%)$ in the surveyed firm were successful in obtaining and accessing the needed data and information from the DW, only two respondents indicated that they were not at all successful, while $56 \%$ indicated somewhat successful and $13 \%$ indicated very successful. In addition to these results, $67 \%$ and $33 \%$ of the respondents rated the importance of the obtained information in performing their job better as vital and somewhat important respectively.

Numerous studies have also shown successful implementation of DW. For example, [66] used a case study and conducted a series of interviews at Continental Airlines. The results showed that the organization has realized an enviable level of DW maturity and significant cumulative benefits. [67], who surveyed 244 members of TDWI, found that $51.2 \%$ of the respondents had at least one DW application and $30.3 \%$ were still in development stage. $17.2 \%$ were still in planning stage and $1.2 \%$ of respondents had no any efforts made in their organizations to implement the DW. This result showed that more than $80 \%$ of respondents had implemented DW.

According to [14], there is a scarcity of empirical studies that examine the DW success. Therefore, this paper investigates the extent to which Jordanian firms implemented DW and the benefits for implementing DW. It is aimed at providing empirical evidence, thereby extending the body of research regarding the implementation of DSSs in general and DW in particular. 


\section{RESULTS, FINDINGS AND DISCUSSION}

As mentioned earlier, the study's sample consists of the Jordanian firms' top management. The results of the study's sample analysis are shown in the figure below (Figure 1). In this figure, the sample results are broken down by responses.

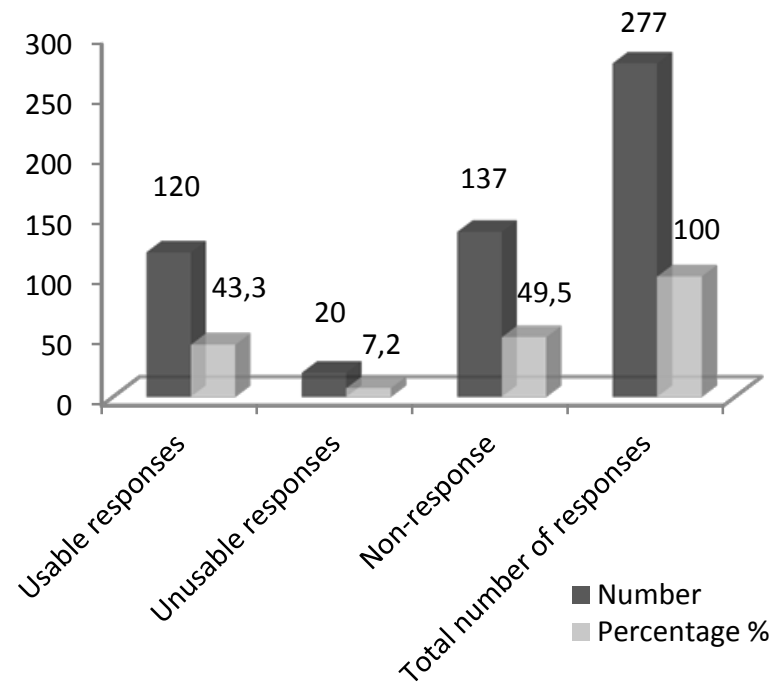

Fig. 1. The analysis of the study's sample (Source: the figures are based on the responses to the questionnaire).

As can be seen from these results, 140 completed questionnaires were returned to the researcher's address with a response rate of $50.5 \%$. According to these figures, usable questionnaires accounts for $43.3 \%$ of the total sample. 20 of the questionnaires were discarded as unreliable, i.e. there were many essential questions missing from the questionnaires. To sum up, all the firms (277), which were listed on ASE at the time of data collection, were selected. 140 filled questionnaires were returned generating $50.5 \%$. This response rate somehow on average comparison to many similar studies such as ([69]; [70]).

The reliability, internal consistency and validity of the Likert scale questions are assessed by using Cronbach's alpha. It was found that Cronbach's alpha is the most popular method for assessing the reliability of scales.

It has been used by many researchers, including [71]. Cronbach's alpha determines the internal consistency of the items in a survey instrument (questionnaire) to assess its reliability. Figure 2 shows Cronbach's alpha for the Likertscale question. In addition, the figure demonstrates the mean, SD, sum of item variances (V) and standard error (SE) for the rating scale question. As can be seen from these figures, Cronbach's alpha coefficient is more than 0.9.

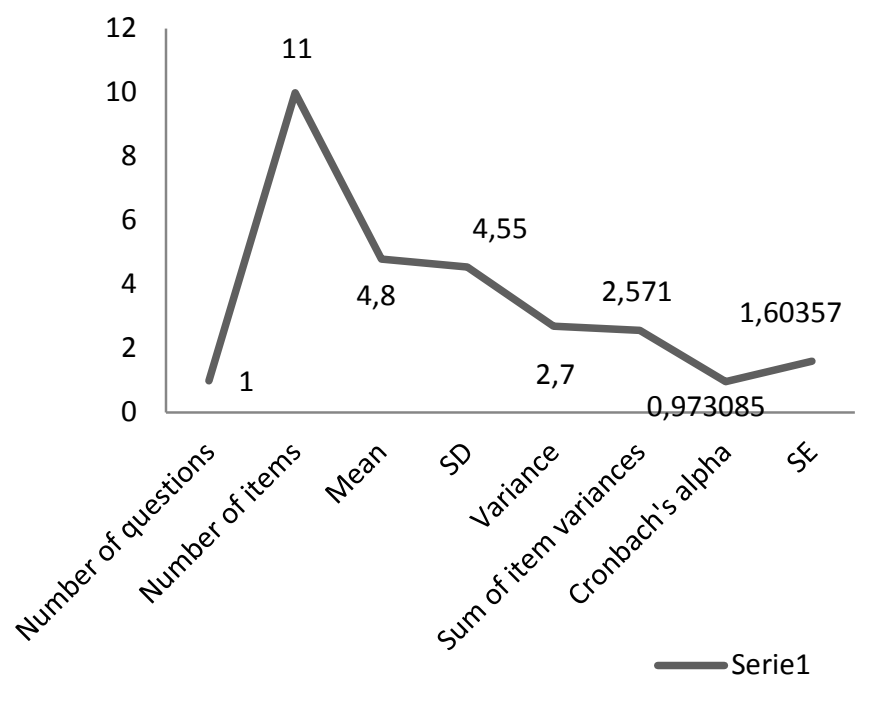

Fig. 2. The statistical analysis of reliability and validity (Source: the figures are based on the responses to the questionnaire).

The respondents, who their firms implemented DW (42 respondents), were solicited for their opinions regarding the actual benefits (which their firms have realized) of implementing the DW. The likely and expected benefits, which were measured on a seven-point scale ranging from 1 (strongly disagree) to 7 (strongly agree), are shown in table (1).

The table shows the mean and SD for all the select benefits. As can be seen from these results, the role of DW's information in enhancing and facilitating the process of decision-making (mean=6.38) was the most important benefit of implementing the DW in the Jordanian firms involved. From the data in the above table, it is apparent that the improvement to decision-making process is the second most widely mentioned benefit of implementing DW.

Other important benefits of implementing DW include more accurate, useful, reliable, complete and relevant information to decision-makers (mean= 6.28), helping decision-makers in taking fact-based decisions $($ mean= 6.26) and more efficient and successful decisions (mean=6.23). Moreover, the figures show clearly that the DW has provided many benefits, including frequent, accessible and timely reports and information to decision-makers (mean=6.11), improved the quality of decisions (mean=6.04), easy access to data and information (mean=6.04) and DW's information is used as a basis for decision-making. According to these figures, Increase in competitive capability (mean=5.57) and better performance measurement (mean= 5.54) were the least important benefits of implementing DW. 
THE BENEFITS OF IMPLEMENTING DW

\begin{tabular}{|c|c|c|c|c|c|}
\hline Benefits of implementing DW & No & Min. & Max. & Mean & SD \\
\hline DW has improved the quality of the decisions & 42 & 4 & 7 & 6.04 & 1.01 \\
\hline DW's information has helped decision-makers in taking fact-based decisions & 42 & 4 & 7 & 6.26 & 0.83 \\
\hline Better performance measurement & 42 & 3 & 7 & 5.54 & 1.26 \\
\hline Easy access to data and information & 42 & 5 & 7 & 6.04 & 0.79 \\
\hline $\begin{array}{l}\text { DW has provided more accurate, useful, reliable, complete and relevant } \\
\text { information to decision-makers }\end{array}$ & 42 & 5 & 7 & 6.28 & 0.81 \\
\hline $\begin{array}{l}\text { DW has provided frequent, accessible and timely reports and information to } \\
\text { decision-makers }\end{array}$ & 42 & 4 & 7 & 6.11 & 0.99 \\
\hline DW's information is used as a basis for decision-making in your firm & 42 & 4 & 7 & 6.02 & 0.92 \\
\hline Increase in competitive capability & 42 & 1 & 7 & 5.57 & 1.67 \\
\hline Improvement to decision-making process & 42 & 5 & 7 & 6.31 & 0.71 \\
\hline DW has led to more efficient and successful decisions & 42 & 4 & 7 & 6.23 & 0.93 \\
\hline DW's information enhances and facilitates the process of decision-making & 42 & 5 & 7 & 6.38 & 0.76 \\
\hline
\end{tabular}

Source: The figures are based on the responses to questionnaire.

In conclusion, the figures clearly lead to the conclusion that the select benefits are highly rated. These results are entirely consistent with other earlier research on DW. For example, [10], who investigated the adoption of DW in Small and Medium Enterprises (SME) In Zimbabwe, found that DW provides a variety of benefits, including the reduction in the overall effort concerning data analysis and reporting, improvements to the reports' quality, more flexible reaction to new information needs and improvement to business decisions through more precise as well as more current data analyses.

Park and Kim [11], who presented a DSS for the management of sewer infrastructure using DW technology, found that the managers, by using DW, could significantly reduce the burden of collecting unnecessary information, easily retrieve managerial information and achieve effective data management. Consequently, the proposed DSS could provide flexible storage of valuable information, reduce subjectivity in decision-making processes, accelerate the pace of data flow, improve the consistency in decisionmaking processes (consistent decisions), and better environment for strategic operation of infrastructure.

\section{CONCLUSION}

The evidences, which are obtained by analyzing the data from the questionnaires, reveal exceptionally remarkable facts, first of all and to some extent, the success of implementing DW in Jordanian firms was a direct result of the benefits which were reaped from using the DW by the managers of Jordanian firms. One consequence of implementing DW was the great role of DW's information in enhancing and facilitating the process of decision-making. The results also showed that the Jordanian firms benefited greatly from implementing DW: These benefits reflected well on the process of decision-making. The results also revealed that the DW is a fruitful source of information. Moreover, the implementation of DW proved to be a success through helping decision-makers in taking fact-based decisions. Based on some of the study's findings, it can be concluded that the implementation of DW did provide frequent, accessible and timely reports and information to decision-makers and easy access to data and information. Furthermore, the DW was lauded by the users for the successful use of its information as a basis for decisionmaking.

This study has humbly contributed to the field of scientific research in general and the field of decision support systems (DSS) in particular in many ways, first of all, the studies on the implementation of DW were nearly all in developed countries. This study was applied in Jordan, therefore, the results of this study made a humble contribution to the existing knowledge in the field of implementing DW worldwide in general and in Jordan in particular.

Second, there is a need for evidences that the DW improves the quality and accessibility to information. Therefore, this study practically investigated whether or not the implementation of DW improves the quality and accessibility to information and facilitates the decisionmakers' tasks. Lastly, Based on extensive literature review, the researchers have identified that firms are often unsuccessful due to a lack of appropriate information. For this reason, this study is one of the few empirical studies which have attempted to examine the effect of DW on decision effectiveness. In addition, previous research has not empirically tested its effectiveness in DSS contexts in Jordanian firms "to the researchers' knowledge".

Despite the usefulness and positive contributions of the study's results, these results should be treated and interpreted with caution. In fact, the study's sample included only the Jordanian firms which are listed on ASE. As a consequence, this might severely restrict the generalization of the results. It is believed that the results of this study might have been dissimilar, if all Jordanian firms have been surveyed. Therefore, prospective researchers are recommended to broaden the scope of their investigation to include all Jordanian firms. 


\section{REFERENCES}

[1] P. Lehmann, and J. Jaszewski, Business terms as a critical success factor for data warehousing, Proceedings of the International Workshop on Design and Management of Data Warehouses (DMDW'99) Heidelberg, Germany, 1999.

[2] K.W. Chau, Y. Cao, M. Anson, and J. Zhang, Application of data warehouse and Decision Support System in construction management, Automation in Construction, 12, 2002, pp. 213-224.

[3] R. L. Hayen, C. D. Rutashobya, and D. E. Vetter, An investigation of the factors affecting data warehousing success, Issues in Information Systems, Vol. 8, No. 2, 2007, pp. 547-53.

[4] M. Mohania, S. Samtani, J. F. Roddick, and Y. Kambayashi, Advances and Research Directions in Data-Warehousing Technology, AJIS, Vol. 7, No. 1, September 1999, pp. 41-59.

[5] J. Ang, and T. S. H. Teo, Management issues in data warehousing: insights from the Housing and Development Board, Decision Support Systems, 29, 2000, pp. 11-20.

[6] B. Shin, An exploratory investigation of system success factors in data warehousing, Journal of the Association for Information Systems, Vol. 4, 2003, pp. 141-170.

[7] Y.-T. Park, An empirical investigation of the effects of data warehousing on decision performance, Information \& Management, 43, 2006, pp. 51-61.

[8] D. Mukherjee, and D. D'Souza, Think phased implementation for successful data warehousing, information systems management, Spring 2003, pp. 82-90.

[9] S. Nilakanta, K. Scheibe, and A. Rai, Dimensional issues in agricultural data warehouse designs, computers and electronics in agriculture, 60, 2008, pp. 263-278.

[10] W. Mtembo, , F. Madzikanda, and T. Musiiwa, An Examination of the Benefits and Challenges of Data Warehouses Adoption in SMEs of Zimbabwe, International Journal of Management \& Business Studiem, Vol. 3, Issue 2, April - June, 2013, pp. 99-100.

[11] T. Park, and H. Kim, A data warehouse-based decision support system for sewer infrastructure management, Automation in Construction, 30, 2013 , pp. $37-49$

[12] G. Shankaranarayanan, and Y. Cai, Supporting data quality management in decision-making, Decision Support Systems 42, 2006, pp. 302-317.

[13] A. Rudra, and E. Yeo, Issues in User Perceptions of Data Quality and Satisfaction in Using a Data Warehouse - An Australian Experience, Proceedings of the 33rd Hawaii International Conference on System Sciences, IEEE 2000, pp. 1-7.

[14] F. Hegazy, and K. Ghorab, The impact of system support on adoption $\&$ diffusion of data warehousing success, 2003, http://www.hicbusiness.org/biz2003proceedings, accessed 31/08/2011.

[15] M. D. Solomon, Ensuring a successful data warehouse initiative, information systems management, Vol. 22, Issue 1, December 2005, pp. 26-36.

[16] A. Aljanabi, A. Alhamami, and B. Alhadidi, Query Dispatching Tool Supporting Fast Access to Data Warehouse, The International Arab Journal of Information Technology, Vol. 10, No. 3, May 2013, pp. 269-275.

[17] M. I. Hwang, and H. Xu, The Effect of Implementation Factors on Data Warehousing Success: An Exploratory Study, Journal of Information, Information Technology, and Organizations, Vol. 2, special section 2007, pp. 1-14.

[18] B. H. Wixom, and H. J. Watson, An empirical investigation of the factors affecting data warehousing success, MIS Quarterly, Vol. 25, No. 1, 2001, pp. 17-41.

[19] E. Gimzauskiene, and L. Valanciene, Efficiency of Performance Measurement System: The Perspective of Decision Making, economics and management, 15, 2010, pp. 917-923.

[20] S. A. Mansouri, D. Gallear, and M. H. Askariazad, Decision support for build-to-order supply chain management through multiobjective optimization, International Journal of Production Economics, 135, 2012, pp. 24-36.

[21] J. P. McKenna, Moving Toward Real-Time Data Warehousing, business intelligence Journal, Vol. 16, No. 3, 2011, pp. 14-19.
[22] N. Au, E. W. T. Ngai, and T. C. E. Cheng Extending the Understanding of End User Information Systems Satisfaction Formation: An Equitable Needs Fulfillment Model Approach, MIS Quarterly, Vol. 32, Issue 1, 2008, pp. 43-66.

[23] N. Rasmussen, P. S. Goldy, and P. O. Solli Financial Business Intelligence Trends, Technology, Software Selection, and Implementation, John Wiley and Sons, Inc., New York, 2002.

[24] H. J. Watson, and B. J. Haley, Data warehousing: A framework and survey of current practices, Journal of Data Warehousing, Vol. 2, No. 1, 1997, pp.10-17.

[25] S. Gatziu, and A. Vavouras, Data Warehousing: Concepts and Mechanisms, Informatik, Informatique 1, 1999.

[26] N. F. Doherty, and G. Doig, The role of enhanced information accessibility in realizing the benefits from data warehousing investments, Journal of Organizational Transformation and Social Change, Vol. 8, No, 2, 2011, pp. 163-182.

[27] C. Ballard, D. Herreman, D. Schau, R. Bell, E. Kim, and A. Valencic, Data Modeling Techniques for Data Warehousing, International Business Machines Corporation(IBM Corp), $1^{\text {st }}$ edition, 1998.

[28] H. J. Watson, C. Fuller and T. Ariyachandra, Data warehouse governance: best practices at blue cross and blue shield of North Carolina, Decision Support Systems archive, Vol. 38, Issue 3, December 2004, pp. 435 - 450.

[29] I. Ahmad, and S. Azhar, "Data Warehousing in Construction: From Conception to Application," Proceedings of the First International Conference on Construction in the Twenty First Century, Miami, Florida, USA, April 2002.

[30] B. List, R. Bruckner, K. Machaczek, and J. Schiefer, A Comparison of Data Warehouse Development Methodologies - Case Study of the Process Warehouse, DEXA, Munich, 2002.

[31] H. R. Nemati, D. M. Steiger, L. S. Iyer, and R. T. Herschel, Knowledge warehouse: an architectural integration of knowledge management, decision support, artificial intelligence and data warehousing, Decision Support Systems, Vol. 33, Issue 2, June 2002, pp. 143-161.

[32] M. V .Mannino, S. N. Hong, and I. J. Choi, Efficiency evaluation of data warehouse operations, Decision Support Systems, Vol. 44, No. 4, 2008, pp. 883-898.

[33] B. Bȩbel, J. Eder, C. Koncilia, T. Morzy, and R. Wrembel, Creation and management of versions in multiversion data warehouse, Proceedings of the 2004 ACM symposium on Applied computing, SAC 2004, March 14-17, Nicosia, Cyprus, pp. 717-723.

[34] T. Brown, Data Warehouse Implementation with the SAS System, SAS Institute Inc., Dallas, TX, 1996, http://www2.sas.com/proceedings/sugi22/DATAWARE/PAPER132.P DF.

[35] K. R Ramamurthy, A. Sen, and A. P. Sinha, An empirical investigation of the key determinants of data warehouse adoption, Decision Support Systems, 44, 2008, pp. 817-841.

[36] S. Nilakanta, K. Scheibe, and A. Rai, Dimensional issues in agricultural data warehouse designs, computers and electronics in agriculture, 60, 2008, pp. 263-278.

[37] S. Graham, The Foundations of Wisdom: A Study of the Financial Impact of Data Warehousing, International Data Corporation (Canada) Ltd, 1996.

[38] P. Vassiliadis, C. Quix, Y. Vassiliou, and M. Jarke, Data Warehouse Process Management, Information Systems, Vol. 26, No. 3, June 2001, pp. 205-236.

[39] J. Chmiel T. Morzy, and R. Wrembel, Multiversion join index for multiversion data warehouse, Information and Software Technology archive, Vol. 51, Issue 1, January 2009, pp. 98-108.

[40] R. Hackathorn, Current Practices in Active Data Warehousing, Bolder Technology, Inc., 2002.

[41] H. Watson, and B. Haley, Managerial Considerations, In Communications of the ACM, Vol. 41, No. 9, September 1998, pp. 32-37.

[42] H. J. Watson, D. Goodhue, and B. H. Wixom, The benefits of data warehousing: why some organizations realize exceptional payoffs, Information \& Management, 2001 (a), pp. 1-12.

[43] H. Watson, T. Ariyachandra, and Jr, R. J. Matyska, Data Warehousing Stages of Growth, Information Systems Management, Vol. 18, Issue 3, June 2001 (b), pp. $42-50$.

[44] J. D. Wells, and T. J. Hess, Understanding decision-making in data warehousing and related decision support systems: An Explanatory 
Study of Customer Relationship Management Application, Information Resources Management Journal, Vol. 15, No. 4, OctoberDecember 2002, pp. 16-32.

[45] H. A. Abdel Hafez, and S. Kamel, Web Based Data Warehouse in the Egyptian Cabinet Information and Decision Support Center, Decision Support in an Uncertain and Complex World: The IFIP TC8/WG8.3 International Conference, 2004, pp. 402-409.

[46] D. L. Rubin, and T. S. Desser, A Data Warehouse for Integrating Radiologic and Pathologic Data, Journal of the American College of Radiology, Vol. 5, No. 3, March 2008, pp. 210-217.

[47] P. K. Mawilmada, Impact of a data warehouse model for improved decision-making process in healthcare. Masters by Research thesis, Queensland University of Technology, October 2011.

[48] A. Ojeda-Castro, M. Ramaswamy, A. Rivera-Collazo, and A. Jumah, Critical Factors For Successful Implementation Of Data Warehouses, Issues in Information Systems, Vol. 12, No. 1, 2011, pp. 88-96.

[49] R. Alshboul, Data Warehouse Explorative Study, Applied Mathematical Sciences, Vol. 6, No. 61, 2012, pp. 3015-3024.

[50] L. Shen, S. Liu, S. Chen, and X. Wang, The Application Research of OLAP in Police Intelligence Decision System, Procedia Engineering 29, 2012, pp. $397-402$.

[51] K. Shams, and M. Farishta, Data warehousing: toward knowledge management, Topics in Health Information Management, Vol. 21, No 3, February 2001, pp. 24-32.

[52] T. Chenoweth, K. Corral, and H. Demirkan, Seven Key Interventions for data warehouse success, Communications of the ACM, Vol. 49, No. 1, January 2006, pp. 115-119.

[53] W. H. DeLone, and E. R. McLean, Information systems success: the quest for the dependent variable, Information Systems Research, Vol. 3, No. 1, 1992, pp. 60-95.

[54] R. L. Kumar, Justifying Data Warehousing Investments, in Data Warehousing and Web Engineering, Shirley Becke (Ed.), 2002, pp. 100-102.

[55] H. J. Watson, J. G. Gerard, L. E. Gonzalez, M. E. Haywood, and D. Fenton, Data warehousing failures: case studies and findings, Journal of Data Warehousing, Vol. 4, No. 1, Spring 1999, pp. 44- 55.

[56] D. Sammon, F. Adam, and F. Carton, Benefit Realisation through ERP: The Re-Emergence of Data Warehousing, Electronic Journal of Information Systems Evaluation, Vol. 6, Issue 2, 2003, pp. 155-16.

[57] M. D. Aguila, and E. Felber, Data Warehouses and Evidence-Based Dental Insurance Benefits, Journal of Evidence Based Dental Practice, Vol. 4, Issue 1, 2004, pp. 113-119.

[58] Devlin, B. Data Warehouse from Architecture to Implementation, Addison Wesley Longman, Inc., 1997.

[59] R. K. Griffin, Data warehousing, Cornell Hotel and Restaurant Administration Quarterly, Vol. 39, No. 4, 1998, pp. 28-40.

[60] N. Wilkoff, T. Pohlmann, R. Hudson, and N. Lambert, The State Of Technology Adoption, Business Technographics North America, May 5 2004, Forrester Research, Inc.

[61] L. Agosta, Hub-and- Spoke Architecture Favored, DM Review, Vol. 15, Issue 3, March 2005, pp. 14-63.
[62] H.-G. Hwang, C.-Y. Ku, D. C. Yen, and C.-C. Cheng, Critical factors influencing the adoption of data warehouse technology: a study of the banking industry in Taiwan, Decision Support Systems, 37, 2004, pp. 1-21.

[63] S. Hong, P. Katerattanakul, S.-K. Hong, and Q. Cao, Usage and perceived impact of data warehouses: a study in Korean financial companies, International Journal of Information Technology \& Decision Making, Vol. 5, No. 2, 2006, pp. 297-315.

[64] L. Agosta, M. Andrews, and M. Ritzmann, The Data Warehouse Satisfaction Survey, Part 1: The Number One Complaint About Data Warehousing, Information Management Special Reports, October 2 2007.

[65] K. L. Merritt, User Satisfaction In Data warehousing: An Empirical Investigation Of Salient Variables, Issues in Information Systems, Vol. 9, No. 2, 2008, pp. 500-508.

[66] B. H. Wixom, H. J. Watson, A. M. Reynolds, and J. A. Hoffer, Continental Airlines Continues to Soar with Business Intelligence, Information Systems Management, 25, 2008, pp. 102-112.

[67] A. Almabhouh, A. R. Saleh, and A. Azizah, Examining the Influence of Relationship Quality on Data Warehouse Success, International Journal of Modeling and Optimization, Vol. 1, No. 5, December 2011, pp. 402-409.

[68] M. G. Lodico, D. T. Spaulding, and K. H. Voegtle, Methods In Educational Research From Theory to Practice, John Wiley \& Sons, Inc., San Francisco, CA, 2006.

[69] B. AL-allak, Evaluating the Adoption and Use of Internet-based Marketing Information Systems to Improve Marketing Intelligence (The Case of Tourism SMEs in Jordan), International Journal of Marketing Studies, Vol. 2, No. 2, November 2010, pp. 87- 101

[70] A. Al Khattab, The Role of Corporate Risk Managers in Country Risk Management: A Survey of Jordanian Multinational Enterprises, International Journal of Business and Management, Vol. 6, No. 1, January 2011, pp. 274-282.

[71] W. Chongruksut, the adoption of activity-based costing in Thailand, doctoral thesis, Faculty of Business and Law, Victoria University, 2002.

[72] Y. W. Lee, D. M. Strong, B. K. Kahn, and R. Y. Wang, AIMQ: a methodology for information quality assessment, Information \& Management 40, 2002, pp.133-146.

[73] A. S. Hardan, and T. M. Shatnawi, Impact of Applying the ABC on Improving the Financial Performance in Telecom Companies, International Journal of Business and Management, Vol. 8, No. 12, 2013, pp.48-61.

[74] S. B. Gerber, and K. V. Finn, Using SPSS For Windows Data Analysis and Graphics, 2nd Edition, Springer Science Business Media, Inc., 2005.

[75] D. George, and P. Mallery, SPSS for Windows Step-by-Step: A Simple Guide and Reference, 14.0 update, 7th Edition 2006, Allyn \& Bacon.

[76] Owoc M. L., Alsqour M., Abdulrhman S. A.: Data Warehouse as a Source of Knowledge Acquisition. An Empirical Study. Proc. of the 2014 Federated Conference on Computer Science and Information Systems, Maria Ganzha, Leszek Maciaszek, Marcin Paprzycki (eds.), pp. 1421-1430, ISSN 2300-5963 